\title{
Effect of dietary $n-3$ series fatty acids on sperm motility duration of rainbow trout (Oncorhynchus mykiss Walbaum, 1792)
}

\author{
Seyma Ozer Kaya ${ }^{1}\left(\mathbb{D}\right.$, Seyfettin Gur ${ }^{1}(\mathbb{D})$, Kenan Koprucu² ${ }^{(\mathbb{D})}$, Gaffari Turk ${ }^{1}$ (D), Mustafa Sonmez ${ }^{1}$ (D), Sinan Ozcan² (D) \\ ${ }^{1}$ Firat University, Faculty of Veterinary Medicine, Department of Reproduction and Artificial Insemination, Elazig, Turkey \\ ${ }^{2}$ Firat University, Faculty of Fisheries, Department of Aquaculture, Elazig, Turkey
}

Correspondence Author: Seyma Ozer Kaya

E-mail: sozer@firat.edu.tr

Received: 10.02 .2020

Accepted: 28.02 .2020

\begin{abstract}
Objective: This study was performed to determine the effect of different ratios of $n-3$ series fatty acids added to the diets of rainbow trout (Oncorhynchus mykiss) on sperm motility duration.

Methods: A total of 48 male rainbow trouts about 3 years of age were used in the study and 4 groups were formed. The one that $n-3$ series fatty acids were not added to the diet was used as control group. $n-3$ series fatty acids were added to the experimental groups diets at the ratios of $1 \%(E 1), 2 \%$ (E2) and 3\% (E3), respectively. Semen was collected by abdominal massage. The time-dependent sperm motility change was detected under the microscope at x400 magnification.

Results: A significant decrease was detected in the motility only at 360th hour in E3 group compared to the control group ( $\mathrm{p}<0.05$ ).

Conclusion: As a result, it was concluded that feeding with diets containing different ratios of $n-3$ series fatty acids had no effect on the motility of rainbow trout semen under in vitro condition.
\end{abstract}

Keywords: Diet, duration of motility, fatty acid, rainbow trout, sperm motility.

\section{INTRODUCTION}

Rainbow trout (Oncorhynchus mykiss), which is a freshwater fish, farming increases year by year in our country depending on its existing potential. Rainbow trout belongs to the Salmonidae family. It matures in 2-3 years and spawns between December and May (1).

The fast growth of the world population leads to a rapid decline in animal protein sources. Therefore, the production of animal proteins should be accelerated. The current biotechnological research contributes to the increase in fish farming worldwide. Recently, studies focused on the yield increased significantly. As in the hatcheries in our country, farmers aim to increase the number of tiddlers, knowledge about the evaluation criteria of the yield characteristics in the brood fishes, which will be used in farming, is critical. Sperm motility is one of the most important sperm parameters. To increase the yield, the use of sperm with good sperm quality is essential (24). The duration spermatogenesis is usually shorter in fish than in mammals. In principle, spermatogenesis can be divided, from a morpho-functional point of view, in three different phases: the mitotic or spermatogonial phase with the different generations of spermatogonia, the meiotic phase with the primary and secondary spermatocytes, and the spermiogenic phase with the haploid spermatids emerging from meiosis and differentiating, without further proliferation, into flagellated spermatozoa (5). Like other living creatures, also fishes need energy for growth, breeding, living, and their physiological activities. Lipids are their main source of energy. Lipids consist of fatty acids and are not water-soluble. Fatty acids are divided into two groups depending on the number of bonds. Fatty acids with one bond are called saturated and with double bonds are called unsaturated fatty acids. In addition, fatty acids with carbon atom number between 18-20 and double bonds between 2-4 are called polyunsaturated fatty acids (PUFA) and fatty acids with more than 20 carbon atom number and more than 4 double bonds are called highly unsaturated fatty acids (HUFA) (6). Like in other fishes, the rainbow trout needs also n-3 and n-6 fatty acids (7). Furthermore, PUFAs like linolenic, linoleic and $\alpha$-linolenic acid are essential fatty acids and disorders related to growth, development, and proliferation may emerge if their need for these fatty acids is not met (6). 
In this study, our objective was to investigate the effect of n-3 series fatty acids, which were added to the compound feed of rainbow trout in different proportions, on the duration of the sperm motility.

\section{METHODS}

This study was conducted in the Cip Fish Breeding Farming of the Firat University Aquaculture Faculty. A total of 48 male rainbow trouts at age 3 were included in the study. The study was conducted in 4 cement ponds (dimensions: $2 \times 1 \times 0.8 \mathrm{~m})$. The study sample was divided into 4 groups. 12 male broodstocks were placed in each pond. The fishes were adapted to the experimental conditions for one month. They were fed with control feed during this period. Then broodstocks were fed for three months three times daily according to the free feeding technique. They fastened for 24 hours before the sperm yield. They were anesthetized before the stripping process ( $5 \mathrm{~mL}$ phenoxyethanol/L) (8).
The abdomen of the dried male broodstocks was manually massaged from front to the back and sperm was yielded (9).

\subsection{Organization and preparation of the study feed}

Soybean meal, corn gluten, anchovy meal, wheat starch, n-3 fatty acid concentrated from the anchovy oil, unrefined sunflower oil, antioxidants, vitamin mixture, mineral mixture, and wheat bran were purchased from a commercial company for the preparation of the study feed.

In the control group, fishes received feed with no added n-3 fatty acids. The experiment groups (E) E1, E2, and E3 received feed with $45 \%$ concentrated raw protein, $3619 \mathrm{kcal} /$ kg metabolized energy and anchovy oil with an n-3 fatty acid concentration of $1 \%, 2 \%$, and $3 \%$ respectively. Besides, we used corn gluten, soybean meal, anchovy meal, and fatty acids as the protein source and unrefined sunflower oil (as a source of $n-6$ fatty acids) $n-3$ fatty acids as the energy source (Table 1) $(6,10)$.

Table 1. Formulation of the experimental diets

\begin{tabular}{|c|c|c|c|c|}
\hline \multirow{2}{*}{ Feed items (\%) } & \multicolumn{4}{|c|}{ Experimental Diets } \\
\hline & Control & Experiment 1 & Experiment 2 & Experiment 3 \\
\hline Anchovy flour $(\% 56,9)$ & 35 & 35 & 35 & 35 \\
\hline Soybean meal $(\% 42,2)$ & 30 & 30 & 30 & 30 \\
\hline Corn gluten $(\% 52,6)$ & 5 & 5 & 5 & 5 \\
\hline Wheat starch $(\% 10,2)$ & 5 & 5 & 5 & 5 \\
\hline $\mathrm{N}-3$ series fatty acid ${ }^{1}$ & - & 1 & 2 & 3 \\
\hline Sunflower oil & 15.2 & 14.2 & 13.2 & 12.2 \\
\hline Antioxidant $^{2}$ & 0.1 & 0.1 & 0.1 & 0.1 \\
\hline Vitamin Mix ${ }^{3}$ & 1 & 1 & 1 & 1 \\
\hline Mineral mix ${ }^{4}$ & 1 & 1 & 1 & 1 \\
\hline Wheat bran & 7.7 & 7.7 & 7.7 & 7.7 \\
\hline
\end{tabular}

${ }^{1} n-3$ series fatty acid (Solgar OMEGA-3 700) was concentrated from anchovy oil; and containing $54.3 \%$ eicosapentaenoic acid (EPA), 37.1\% docosahexaenoic acid (DHA) and $8.6 \%$ other $n-3$ series fatty acids (docosapentaenoic, linolenic, stearidonic acid).

${ }^{2}$ Butylene Hydroxy Toluene (BHT); $125.000 \mathrm{mg} / \mathrm{kg}$.

${ }^{3}$ Vitamin Mix (as active ingredient per $1 \mathrm{~kg}$ Rovimix 107); Vitamin A $250.000 \mathrm{IU}$, vitamin D3 $240.000 \mathrm{IU}$, vitamin E $10.000 \mathrm{IU}$, vitamin K $3.000 \mathrm{mg}$, vitamin B1 $1.000 \mathrm{mg}$, vitamin B2 $3.000 \mathrm{mg}$, vitamin B6 $2.000 \mathrm{mg}$, vitamin B12 $4 \mathrm{mg}$, choline chloride $100.000 \mathrm{mg}$, vitamin C $6.000 \mathrm{mg}$, niacin $30.000 \mathrm{mg}$, calcium d-pantothenate $10.000 \mathrm{mg}$, folic acid $600 \mathrm{mg}$, d-biotin $200 \mathrm{mg}$.

${ }^{4}$ Mineral Mix (mg/kg); Manganese 1.300, zinc 3.000, iron 6.000, copper 300, iodine 110, potassium 70, phosphorus 60, selenium 30, cobalt 20 , magnesium 5.

\subsection{Determination of the sperm motility and sperm duration}

After semen collection, semen was stored in the cooling cabinet at $4{ }^{\circ} \mathrm{C}$. Sperm motility determination was done at certain intervals until motility was exhausted. In order to determine the motility of the semen samples obtained from the fishes, $2 \mathrm{ml}$ of the $119 \mathrm{mmol} \mathrm{NaCl}$ solution was poured in a tube. Then 1 drop semen was added and mixed. One drop of this mixture put on a slide glass and covered with a cover glass. The motility rate (\%) was determined under a mirror microscope with a 400x magnification. The time-dependent change in this rate was investigated.
The study data were expressed in mean values and standard error of means ( \pm SEM) after the statistical analysis. The software package SPSS (22.0, Chicago, IL, USA) was used for the comparative statistical analysis. For all analyses, $\mathrm{p}<0.05$ was considered statistically significant.

Regarding the motility, non-parametric Kruskal-Wallis variance analysis was used for the intergroup comparisons and non-parametric Mann-Whitney $U$ test for the paired comparisons. 


\section{RESULTS}

The mean motility rate (\%) according to time (min) in rainbow trout in the control and experimental groups, which were fed with diets containing different $n-3$ series fatty acid concentrations, were summarized in Table 2.

The sperm motility was numerically higher in the experimental groups than the control group during first $30^{\text {th }}$ minute. At the $60^{\text {th }}$ minute, while the motility value in the E3 group decreased numerically compared to the other groups, E1, E2 remained the same with the control. The numerical decrease in sperm motility of the experimental groups continued after $120^{\text {th }}$ minute compared to the control group.

A significant decrease was detected in the motility only at $360^{\text {th }}$ hour in $\mathrm{E} 3$ group compared to the control group $(p<0.05)$.

Table 2. Average ( \pm SEM) motility (\%) values of control and experimental groups according to time (minute)

\begin{tabular}{|c|c|c|c|c|c|c|c|c|c|c|c|c|c|c|}
\hline & Begining & 5th $\mathrm{min}$ & 10th min & 15th min & 20th min & 25th min & 30th min & 60th min & 120th $\mathrm{min}$ & 180th $\mathrm{min}$ & 240th min & 300th min & 360th min & 420th $\mathrm{min}$ \\
\hline Control & $80.00 \pm 5.77$ & $76.66 \pm 3.33$ & $76.66 \pm 3.33$ & $73.33 \pm 3.33$ & $70.00 \pm 0.00$ & $70.00 \pm 0.00$ & $70.00 \pm 0.00$ & $70.00 \pm 0.00$ & $60.00 \pm 0.00$ & $60.00 \pm 0.00$ & $53.33 \pm 3.33$ & $40.00 \pm 5.77$ & $26.66 \pm 3.33^{a}$ & $3.33 \pm 3.33$ \\
\hline E1 & $88.75 \pm 3.14$ & $80.00 \pm 0.00$ & $77.50 \pm 2.50$ & $75.00 \pm 2.88$ & $72.50 \pm 2.50$ & $72.50 \pm 2.50$ & $70.00 \pm 0.00$ & $70.00 \pm 0.00$ & $65.00 \pm 2.88$ & $55.00 \pm 2.88$ & $55.00 \pm 2.88$ & $40.00 \pm 4.08$ & $20.00 \pm 4.08^{a}$ & $0.0 \pm 0.00$ \\
\hline E2 & $88.33 \pm 4.40$ & $86.66 \pm 3.33$ & $86.66 \pm 3.33$ & $86.66 \pm 3.33$ & $80.00 \pm 5.77$ & $80.00 \pm 5.77$ & $73.33 \pm 12.0$ & $70.00 \pm 10.0$ & $56.66 \pm 8.81$ & $53.33 \pm 6.66$ & $53.33 \pm 6.66$ & $33.33 \pm 6.66$ & $20.00 \pm 5.77^{a}$ & $3.33 \pm 3.33$ \\
\hline E3 & $88.33 \pm 4.40$ & $80.00 \pm 5.77$ & $80.00 \pm 5.77$ & $76.66 \pm 6.66$ & $76.66 \pm 6.66$ & $76.66 \pm 6.66$ & $73.33 \pm 3.33$ & $63.33 \pm 3.33$ & $53.33 \pm 3.33$ & $43.33 \pm 8.81$ & $43.33 \pm 8.81$ & $26.66 \pm 6.66$ & $3.33 \pm 1.66^{b}$ & $0.0 \pm 0.00$ \\
\hline
\end{tabular}

$a$ and $b$ : Differents letters within a column showed significant differences between groups $(p<0.05)$

\section{DISCUSSION}

The yield of good quality sperm is one of the main goals of fish farming. Several biotic and abiotic factors affect the yield and quality of the sperm. The nutrition of the broodstocks has a direct effect on sperm quality. Although nutrition has an important effect on reproductive physiology, there is only limited evidence that these changes can affect sperm quality. Fatty acids especially PUFAs, n-3 series fatty acids and their derivatives can affect the number of eggs $(11,12)$.

In bony fish species, which are reproduced via external fertilization, the spermatozoon activity is short and reaches the maximum speed after the dilution. Besides, their speed declines during motion. The very short duration of sperm motility is the main reason for the low fertilization rate in salmonids (13). The mean duration of the sperm motility is 20-25 seconds in trouts and more than 1 minute in carps (14). The duration of spermatozoon motility in the active rainbow trouts is 30-35 seconds during the spawning season. The duration of motility drops up to 15 seconds at the end of the season (15).

In our study, the duration of motility was very long compared to the previous studies and the vitality of the rainbow trout spermatozoon was preserved up to 360 minutes. We believe that the high extracellular $\mathrm{K}^{+}$concentration inhibited the spermatozoon motility in the previous studies. Therefore, we believe that the spermatozoon motility can be activated with the extracellular $\mathrm{K}^{+}$diluent. This diluent causes membrane hyperplasia, which triggers the activation (16). Besides, osmotic pressure is one of the factors determining sperm activation and is commonly considered as a triggering factor for the initiation of sperm motility. Motility starts at a higher osmotic pressure in saltwater fishes compared to the freshwater species (17). Furthermore, as the duration of motility is short in the trout spermatozoon, the motility measurement should be performed quickly. The difference in the motile lifespans between the studies may depend in general on the environmental factors and the temperature in the laboratory.
The lipid and fatty acid composition of the feed are defined as the main factor for successful reproduction of fishes and their survival (18). As the lipid composition is closely related to the spermatozoon quality, its quantity in the feed is important. Lahnsteiner et al. (11) investigated the compositions of the total fatty acids in the seminal plasma and sperm in trouts and found saturated fatty acids such as myristic acid, palmitic acid, and stearic acid and unsaturated fatty acids like oleic acid, vaccenic acid, and linolenic acid. Another study reported that free fatty acids and sterols were the main lipid components in the seminal fluid and stated that the fatty acid composition of the sperm was affected by the nutrition (19). The investigators found out that the n-3 PUFA deficiency in the feed affected the sperm motility and the motility was lower compared to the controls. In our study, we determined that in the group, in which $3 \%$ of fatty acid was added to the diet, the sperm motility impaired the sperm lifespan only at $360^{\text {th }}$ minute.

In salmonids, lipids are the main energy source for sperms and therefore they are important for the preservation of sperm vitality (11). Fatty acid oxidation occurs as a result of adenosine triphosphate production, which is stored in the sperm cell membrane, mitochondria, middle segment, and tail of the sperms. Therefore, the increase of the fatty acids in the testicular cells stimulates the sperm production capacity in testicles and thus the rate of the sperm survival and sperm motility increase (20). In our study, a significant decrease was detected in the motility from only at $360^{\text {th }}$ hour in E3 group compared to the control group. Along with several factors affecting sperm survival, a high concentration of fatty acids increases the metabolism in sperms and leads to an early decline of the motility, which may be considered as an additional factor.

In astudy conducted with the European seabass (Dicentrarchus labrax), Asturiano et al. (21) observed that diets containing PUFA had a positive effect on the reproduction parameters including sperm volume and density. In another study 
conducted with Barbus barbus species, Alavi et al. (22) fed the fishes with PUFA-containing diet during the breeding season. However, their investigation on the sperm quality demonstrated that different diets did not affect sperm volume, total sperm quantity, concentration, and motility. In addition, in another study focused on Carassius auratus, it was determined that in vitro essential fatty acids stimulated the testicular testosterone production and affected theprostaglandins (18). Thus, the production of the steroid hormones declines in fatty acid deficiency, spermiation time is delayed and consequently, the fertilization rate may decline Lahnsteiner et al. (11) investigated the fatty acids during the short time preservation of sperm in rainbow trout and reported that the sperm survival prolonged and had a positive effect on sperm motility and consequently on fertility.

\section{CONCLUSION}

As a result, it was concluded that feeding with diet including different concentrations of $n-3$ series fatty acids has no effect on motility in rainbow trout semen under in vitro conditions.

\section{REFERENCES}

[1] Çelikkale MS. İçsu Balıkları ve Yetiştiriciliği. Karadeniz Teknik Üniversitesi, Sürmene Deniz Bilimleri ve Teknolojisi Yüksekokulu, Fakülte Yayın No: 2, Trabzon; 1988.

[2] Dreanno C, Cosson J, Suquet M, Seguin F, Dorange G, Billard R. Nucleotide content, oxidative phosphorylation, morphology and fertilizing capacity of turbot (psetta maxima) spermatozoa during the motility period. Mol Reprod Dev 1999; 53:230-243.

[3] Okumuş I. Rainbow trout broodstock management and seed production in Turkey: present practices, constraints and the future. Turkish J Fish Aqua Sci 2003; 2:41-56.

[4] Yavuz H. Farklı kromozomlara (XX ve XY) sahip erkek gökkuşağı alabalığı (Oncorhynchus mykiss) spermlerinin dölleme kalitesi. Yüksek Lisans Tezi. Fırat Üniversitesi Sağıık Bilimleri Enstitüsü, Elazığ. 2012.

[5] Cosson J. Fish sperm physiology: Structure, factors regulating motility, and motility evaluation. Borkurt $Y$, editor. Biological Research in Aquatic Science. IntechOpen; 2019.p.1-26.

[6] Sargent JR, Toche DR, Bell JG. The Lipids. Halver JE, Hardy RW, editors. Fish Nutrition. USA: San Diego; 2002.p.182-257.

[7] Goddard S. Feed Management in Intensive Aquaculture, $1^{\text {st }}$ ed. New York: Chapman \& Hall Press; 1996.

[8] Mattson NS, Riple TH. Metomidate, a better anaesthetic for cod (Gadus morhua) in comparison with benzocain, MS-222, choloro butanol and phenoxyethanol, Aquaculture 1989; 83:89-94.

[9] Munkittrick KR, Moccia RD. Seasonal changes in the quality of rainbow trout (Salmo gairdneri) semen: Effect of a delay in stripping on sprmatocrit, motility, volume and seminal plasma constituents. Aquaculture 1987; 64:147-156.

[10] National Research Council (NRC). Nutrient Requirements of Fish, National Academy Press, Washington DC. 1999.

[11] Lahnsteiner F, Mansour N, McNiven M A, Richrdson GF. Fatty acids of rainbow trout (Oncorhynchus mykiss) semen: Composition and effects on sperm functionality. Aquaculture 2009; 298:118-124.

[12] Huang X, Yin Y, Shi Z, Li W, Zhou H, Lv W. Lipid content and fatty acid composition in wild-caught silver pomfret (Pampus argenteus) broodstocks: effects on gonad development. Aquaculture 2010; 310:192-199.

[13] Aas GH, Refstie T, Gjerde B. Evaluation of milt quality of atlantic salmon. Aquaculture 1991; 95:125-132.

[14] Bromage NR, Roberts RJ. Broodstock Management and Egg and Larval Quality. $1^{\text {st }}$ ed. Cambridge: Wiley-Blackwell Science Ltd.; 1995.

[15] Benau D, Terner C. Initiation prolongation and reactivation of the motility of salmonid spermatozoa. Gamete Res 1980; 3:247-257.

[16] Boitano S, Omoto CK. Membrane hyperpolarization activates trout sperm without an increase in intracellular pH. J Cell Sci 1991; 98:343-349.

[17] Chambeyron F, Zohar Y. A diluent for sperm cryopreservation of gilthead seabream, Sparus aurata. Aquaculture 1990; 90:345-352.

[18] Izquierdo MS, Fernandez-Palacios H, Tacon AGJ. Effect of broodstock nutrition on reproductive performance of fish. Aquaculture 2001; 197:25-42.

[19] Vassallo-Agius R, Watanabe Takeshi Yoshizaki G, Satoh S, Takeuchi Y. Quality of eggs and spermatozoa of rainbow trout fed an n-3 essential fatty acid-deficient diet and its effects on the lipid and fatty acid components of eggs, semen and livers. Fisheries Sci 2001; 67:818-827.

[20] Frøyland L, Lie $\varnothing$, Berge RK. Mitochondrial and peroxisomal $\beta$-oxidation capacities in various tissues from atlantic salmon salmo salar. Aquacult Nutr 2000; 6:85-89.

[21] Asturiano JF, Sorbera LA, Carrillo M, Zanuy S, Ramos J, Navarro JC, Bromage N. Reproductive performance in male European sea bass (Dicentrarchus labrax, L.) fed two PUFAenriched experimental diets: a comparison with males fed a wet diet. Aquaculture 2001; 194:173-190.

[22] Alavi SMH, Psenicka M, Polica T, Rodina M, Hamackova J, Kozak P, Linhart O. Sperm quality in male Barbus barbus L. fed different diets during the spawning season. Fish Physiol Biochem 2009; 35:683-693. 